impulsando todo tipo de estudios e investigaciones relacionados con el tratamiento del Karate como disciplina científica dentro y fuera de Japón.

Es de esperar que la Editorial Tutor saque a la luz la totalidad de volúmenes que componen la colección Karate Superior en un breve espacio de tiempo, ya que la acogida que en su día tuvo la edición inicial entre los practicantes de Karate fue de absoluto reconocimiento de la misma.

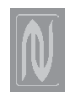

\section{El libro del Aikido}

Por John Stevens

Barcelona: Editorial Kairós, 2002

144 páginas. $14 \times 22 \mathrm{~cm}$. Ilustraciones

I.S.B.N.: 84-7245-523-8 • $10 €$

Disponible en:

Editorial Kairós

C/ Numancia, 117-121

08029 Barcelona (España)

Telf.: +34 4949440

Fax: +34 4105166

E-mail: info@editorial.com

http://www.editorialkairos.com

\section{Revisión por José Santos Nalda Albiac}

Este libro de John Stevens se estructura en cuatro partes que tratan de dar una visión del Fundador del Aikido y de su obra.

En la primera parte describe los rasgos mas notables de la biografía de Morihei Ueshiba, cuyo nacimiento en la villa de Tanabe, situada a unos 300 kilómetros de la montaña sagrada de Kumano, parece determinar el carácter religioso que habría de marcar a este hombre, y del que hizo gala a partir de la época en la que conoció al monje Onisaburo Deguchi de la secta OmotoKyo.

Relata Stevens que Ueshiba tuvo una infancia enfermiza, pero en la adolescencia su férrea voluntad le llevo a realizar toda suerte de trabajos y ejercicios para fortalecer su cuerpo. Ya adulto quiso ser soldado y alistarse para la guerra ruso-japonesa, pero fue rechazado en el examen físico al no alcanzar la estatura mínima requerida. Quería ser soldado y servir a su país, así que se col- gaba de los árboles con grandes pesos atados a sus piernas para estirarse, y con tan rudimentario sistema logró su propósito, ya que al presentarse a un nuevo reconocimiento fue admitido y destinado a un regimiento de infantería. Era habitual en él esforzarse al máximo en todas las tareas, buscando sobrepasar y ampliar sus límites físicos y mentales, y en cierto modo lo consiguió dada la fama de hombre extraordinario que le atribuían sus coetáneos.

Morihei Ueshiba, después de haber frecuentado numerosas escuelas de Bu-Jutsu, dijo en cierta ocasión: "practiqué mas de treinta artes marciales, la mayoría durante menos de tres meses". John Stevens juzga este hecho de manera muy benevolente, afirmando que le bastaba este tiempo para dominar los estilos de tantas escuelas. Nuestro juicio, mas prudente, nos lleva a reflexionar sobre lo que hoy aprende un aikidoka en tres meses, y la realidad nos demuestra que es bien poco...

La búsqueda de Ueshiba fue siempre más espiritual que marcial, y aunque había logrado una gran destreza y eficacia en el Aiki-Jutsu, buscaba algo mas allá de lo físico y lo táctico para resolver los conflictos; buscaba encontrar el comportamiento idóneo ante la agresividad ajena. Así, en Ayabe conoció a Onisaburo Deguchi, y quedó cautivado por los conocimientos esotéricos de este monje, o chamán, de la secta Omoto-Kyo, hasta el punto de afiliarse a ella y seguir por mucho tiempo las enseñanzas de esta religión. Empatizó tanto con Onisaburo que no dudó en acompañarle en un largo y peligroso viaje a Mongolia con fines altamente utópicos, pero fracasó estrepitosamente. Fueron capturados y estuvieron a punto de perder la vida.

John Stevens continúa exponiendo a grandes rasgos los hechos mas sobresalientes de la vida de Morihei, que por otra parte el lector encontrará en muchos de los libros que se han escrito sobre los primeros tiempos del Aikido. Ueshiba presumía en sus mejores años, de estar siempre alerta, y les decía a sus alumnos: "Si alguna vez me sorprendéis desprevenido os daré una licencia para enseñar...”. En la última etapa de su vida, ocupaba su tiempo en meditar, estudiar y rezar, además de practicar o enseñar Aikido cuando sus achaques se lo permitían, y sus explicaciones eran tan "esotéricas" que los alumnos se quejaban de no entenderlas y aburrirse con ellas...

Sintetizando al extremo sus enseñanzas, les proponía a sus seguidores optar por:

- El entendimiento, en vez de la confrontación.

- Hacer de cada momento de la vida ordinaria un acto de culto.

- Llevar una vida sana, y darse un tiempo para meditar.

- Cuidar el medio ambiente porque el Universo es una única familia.

La segunda parte del libro describe la parte técnica del Aikido, cuyo objetivo es múltiple: fortalecer el cuerpo, usar racionalmente la energía, disciplinar la mente, y pulir el espíritu... Es un noble propósito, pero la dificultad estriba en que después de Ueshiba, nadie enseña de manera práctica como conseguir todas esas metas.

Todos pueden practicar Aikido, no se discrimina a nadie, ni por la edad, el sexo, la condición física, la experiencia, etc. porque es susceptible de adaptarse a las posibilidades de cada persona, y en consecuencia, su aprendizaje se puede prolongar hasta edades avanzadas.

Muchas de las técnicas de este arte marcial tienen su origen en el antiguo Ken jutsu, o formas de atacar y defenderse con una katana, y sus bases se estructuran en torno a:

- La guardia o, Kamae (la postura del cuerpo, y la actitud de la mente).

- La distancia de seguridad o, Ma ai.

- El momento oportuno para actuar, o De ai.

- La atención permanente, y la disponibilidad inmediata, o Zanshin.

- El atemi, sin el cual muchas técnicas no serían posibles

- El control del tono muscular

- La sincronía respiración-movimiento, o Iki ai.

La actitud mental libre de pensamientos y emociones, o Mushin.

El autor del libro sigue exponiendo, el modo en que comienzan y acaban los entrenamientos, con un saludo de ritual, las formas de prepararse para la clase (el calentamiento o AikiTaiso), la alternancia de los practicantes en el rol de Uke y de Nage, la nece- 
sidad emitir el Kiai, o grito penetrante que paraliza al oponente, las formas de caer o Ukemis, aunque no explica los detalles técnicos, y acaba describiendo las técnicas fundamentales del Aikido, así como las diferentes formas, o situaciones de adiestramiento.

Sigue la tercera parte, exponiendo la filosofía en la que Morihei Ueshiba quiso fundamentar su arte marcial. Morihei era un hombre profundamente religioso, y cada mañana y cada noche ofrecía sus plegarias al "Gran Espíritu del Aikido", pues estaba totalmente persuadido de que toda persona es "un templo viviente de lo divino". También practicaba con asiduidad el rito de "Misogi", o purificación del cuerpo y de la mente, bajo el chorro frío del agua de una cascada, que simboliza el "regreso a un estado de pureza sencilla", y cuyo objetivo es "recrear el mundo continuamente, para hacer que cada día sea nuevo". En consecuencia, proponía a sus alumnos que cultivasen su espíritu por medio de la plegaria y la meditación, para llegar al conocimiento de si mismos, como la mejor vía para asimilar la filosofía del Aikido.

Entre otros muchos propósitos, en los escritos del creador del Aikido se encuentran estas enseñanzas: "La verdadera victoria es la victoria de uno mismo, y aprender a ganar sin luchar". "El Universo es nuestro gran maestro". "El Aiki es una fuente inagotable de sabiduría". "Hemos de aprender a unirnos con la fuerza vital". "Lo divino no existe sólo allá arriba, en el cielo, sino que está aquí mismo, y por tanto estamos siempre en un estado de gracia divina". "La práctica del Aikido es un acto de fe, una creencia en el poder de la no-violencia". "En el Budo verdadero los adversarios no existen, no hay enemigos".

La lectura de las páginas que contienen esta filosofía inducen a la reflexión y a constatar que una gran parte de los aikidokas de hoy tampoco han entendido el mensaje de Ueshiba, por más que todos presumen de seguir la Vía del Aikido. Claro que, en su descargo, se podría decir que no abundan los maestros que enseñen de verdad el modo de aplicar estas enseñanzas a la vida cotidiana.

La última o cuarta parte del libro es la más breve y se limita a dar noticia de las principales escuelas, que a la muerte de Ueshiba fueron creando sus principales alumnos, tales como Iwama Ryu, de Morihiro Saito; Ki society Aikido, de Koichi Tohei; Yoshinkan Aikido, de Gozo Shioda; Tomiki Aikido, de Kenji Tomiki; y Yoseikan Budo, de Mochizuki. Sigue una extensa bibliografía de libros en inglés sobre el arte del Aikido y un glosario de términos japoneses propios del Budo, y su traducción al español. El libro está ilustrado con abundantes fotos históricas de Morihei Ueshiba practicando Aikido, en diferentes épocas de su vida, y algunas caligrafías con sentencias filosóficas, realizadas por él.

También aparecen fotos de John Stevens realizando técnicas de Aikido.

El lector no encontrará en esta pequeña obra, por tanto, series técnicas de fotos demostrando la ejecución de las técnicas del programa de grados, ya que no es un libro técnico, sino un pequeño homenaje de reconocimiento que el autor quiere rendir a su apreciado maestro Morihei Ueshiba.

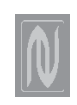

\section{Qi Gong, La Vía del Sosiego}

Por Liu Dong

Barcelona: Editorial Kairós, 2000

178 páginas, $14 \times 22 \mathrm{~cm}$. Ilustraciones I.S.B.N.: 84-7245-474-6 $12 €$

Disponible en:

Editorial Kairós

C/ Numancia, 117-121

08029 Barcelona (España)

Telf.: +34 4949440

Fax: +34 4105166

E-mail: info@editorial.com

http://www.editorialkairos.com

\section{Revisión por Héctor P. Fariña López}

Estamos frente a un libro dividido en dos partes. Una primera y claramente predominante, de carácter filosóficodivulgativo, donde el autor defiende y diferencia lo que entiende por verdadero Qi Gong, que ya desde el Prefacio anuncia como "Una forma de comportamiento cuya justificación se basa en un gran pensamiento filosófico, y que tiene como objetivo mostrarnos el camino hacia el conocimiento de la naturaleza humana, permitirnos tomar conciencia del valor de la vida y de sus límites, y guiarnos por la senda de la sabiduría”. Si bien habla del Qi Gong como parte de la Medicina Tradicional China, vemos que este va mucho más allá de sus fines preventivos y/o terapéuticos.

En esta primera parte se desarrollan conceptos de la medicina Tradicional China enlazados con lo que denomina "trípticos fundamentales de la filosofía china", como "las tres joyas del cielo, tierra y ser humano, las tres armonizaciones del Qi Gong, los tres niveles del pensamiento, la apertura de los tres puntos, etc.", terminando con las "tres prácticas del Qi Gong", donde diferencia una vez mas lo que considera una verdadera práctica frente al Qi Gong de las Artes Marciales o al Qi Gong Musical. El primero porque no es seguro que sea beneficioso para la salud si se priman objetivos marciales, error que no cometerán, según el autor, los verdaderos Maestros de estas Artes, y en el segundo por ser unos simples ejercicios de relajación donde, por ejemplo, la música no permite la quietud mental indispensable para una verdadera práctica. También cita las diferentes Escuelas de la Antigüedad, ya que la denominación de Qi Gong es relativamente reciente y engloba diferentes sistemas.

En esta primera parte siempre están presentes referencias al pensamiento Taoísta y a algo muy habitual en él como son las constantes alusiones a los antepasados y a la antigüedad, e incluso explicaciones de como fueron originalmente estas prácticas o cómo sus antiguos practicantes llegaron a descubrir aspectos como por ejemplo las "horas sensibles" para su ejecución de acuerdo a las variaciones cíclicas en la naturaleza y en el cuerpo (YinYang), su representación con los hexagramas, las influencias del clima, estaciones, fenómenos atmosféricos, etc.

Son constantes las relaciones con los meridianos de acupuntura, lo que hace que quien no tenga cierto conocimiento de ellos se encuentre falto de información, y también hay algunas 